\title{
A Case Study: The Effect of Flooring Renovation with Adsorptive Cloth on the Residual Emissions of 2-ethyl-1- hexanol and C9-C10 Alcohols
}

\author{
Miia J. Pitkäranta ${ }^{1, *}$, and Timo Lehtimaa ${ }^{2}$ \\ ${ }^{1}$ Vahanen Building Physics ltd, Finland \\ ${ }^{2}$ Insinööritoimisto Sulin Oy, Finland
}

\begin{abstract}
This paper presents a renovation case study of a multi-storey building with initially elevated indoor air concentrations of 2-ethyl-1-hexanol and C9-C10 alcohols originating from PVC flooring. The main aim of the study was to determine the effectivity of renovation that included the use of a novel renovation material, cTrap adsorption cloth, in reducing the surface emissions and indoor air concentrations of the named compounds. Indoor air concentrations and surface emission rates of volatile organic compounds (VOC) were measured in the case building before and after renovation according to ISO160006 and NT Build 484 standards. The results show that the measured indoor air concentrations of the alcohols decreased to ca. $1 / 10$ of the original concentration, and the surface emission rates dropped below the determination limit after the renovation.
\end{abstract}

\section{Introduction}

Elevated emissions of volatile organic compounds (VOC) from moisture damaged or low-quality building materials may cause unsatisfactory indoor air [1]. Causing not only bad odours and musty indoor air, VOC emissions have been associated with different kinds of symptoms such as asthma and respiratory irritation [1, 2]. The compound 2-ethyl-hexanol (2-EH) is a common marker substance of indoor air quality problems caused by the alkaline degradation of the plasticizers 2diethylhexylphthalate (DEHP) and diethylhexyldiapate (DEHA) used in plastic flooring materials, as well as certain water-based acrylate glues [2,3,4]. Plastic floorings that have been manufactured with newer plasticizers (commonly DIDN, DIDP or DINCH) emit longer chain $\mathrm{C} 9-\mathrm{C} 10$ alcohol isomers as the decay product. The decay process, which is happening in the glue and at the lower part of plastic flooring, is caused by excess moisture and catalysed by strong alkalinity of the substrate, i.e. the concrete or screed product. 2-EH is also used as an additive in some materials, so it can also be found emitting to indoor air from undamaged materials, yet usually in low amounts.

The usual method of renovating degraded plastic floorings is to remove the flooring material, glue and the screed surface and install new surface materials. In this type of repair, the residual VOC emissions that have been adsorbed in the underlaying concrete (sink effect) may cause issues even when the original emission source, in this case the flooring and its glue have been removed [2]. To control these residual emissions several additional repair methods, such as milling off all screed, milling or sanding the surface of the concrete, ventilation, heating (bake-out), and/or encapsulation of the surface with gas tight products (usually epoxies and other moisture barrier materials) or installation of ventilated floors have been used [2,5]. The downsides of these methods are the long timespan of renovation because of extended ventilation and multiple work tasks, high costs, noise and dust production from milling / sanding, and the adsorption of the VOCs to surrounding materials during the bake-out. Also, emissions from the encapsulating materials (e.g. epoxies) themselves may be of concern, and the low water vapour permeability may in some cases harmfully interfere with the original moisture behaviour of the structure. The abovementioned matters may limit or preclude the use of these repair methods.

A functional cloth (cTrap) has been developed to stop and bind different kinds of surface emissions at their source, while being highly permeable for water vapour. The product is installed mechanically on top of the source of the emissions, commonly walls, floors and ceilings. The product consists of protective surface layers and an adsorptive and an airtight polymer core layer in between. In laboratory tests the product has blocked $87-100 \%$ (on average $98 \%$ ) of the emissions of common VOCs, depending on the individual compound and test condition $\left(\mathrm{T} 30-40{ }^{\circ} \mathrm{C}, 35-85 \% \mathrm{RH}\right)$. The assessment has included several substances relevant to IAQ, e.g. formaldehyde, 2-EH, TXIB, 2-chloroanisole and several compounds defined as microbial volatiles (MVOC). In sensory assessment, the product has diminished the perceived odours, both in renovated problem buildings and laboratory tests. The reported

\footnotetext{
* Corresponding author: miia.pitkaranta@vahanen.com
} 
water vapour resistance of cTrap is $267 \mathrm{~s} / \mathrm{m}$ in $33 \% \mathrm{RH}$ and $177 \mathrm{~s} / \mathrm{m}$ in $85 \%$ RH. $[6,7]$

The advantages of cTrap are good pace of the installation (fewer working hours / installed square meter) and the (product related) dust free installation. Installation of the product itself causes no odours or emissions and according to the manufacturer has been perceived good for people who are sensitive to material emissions. Mechanical installation (no glue) on top of intact old material surface is possible can be advantageous in renovations of certain historically valuable buildings and surfaces. In Finland the cloth has been installed on materials with measured elevated emissions of VOCs such as 2-EH, n-butanol and 2,2,4trimetyl-1,3-pentanediol-di-isobutyrate (TXIB). The product shows promise in controlling various IAQ affecting surface emissions. However, little published information is available on the performance of the product in addition to product developer's research. This report presents results from a case building, in which the cTrap product was used as a part of the plastic flooring problem renovation.

\section{Materials and methods}

\subsection{The case building}

The studied case object was a multi-storey house of approximately 60 apartments, built three years before the start of the investigation. All the apartments had similar glued plastic flooring with a built-in acoustic underlay. The investigations were initiated by complaints of bad indoor air quality from many residents. Based on the following indoor air and moisture measurements, as well as technical assessment of the building structures and condition, deterioration of the flooring material was identified as the most likely cause for bad indoor air quality; measurements taken from indoor air and from floor surfaces indicated elevated emissions of 2-ethylhexanol and C9 - C10 alcohols.

Case apartments were renovated by using two alternative repair methods. In 'repair method 1' the plastic flooring was taken away; the carpet glue and thin layer of the screed were removed by milling. After this the surfaces were left to be ventilated for a few days at most. New primer product and screed layer was then installed on top of the old levelling product. On top of this was installed cTrap and a laminate flooring. The cTrap functions as a sound barrier layer so an additional acoustic insulation was not needed (figure 1). 'Repair method 2' was similar to the 1st method, but a deeper layer (ca. $5 \mathrm{~mm}$ ) of the old screed was removed and the floor surface was then heated to $30-40{ }^{\circ} \mathrm{C}$ and ventilated for ca. three weeks before installing new screed, cTrap and the flooring material.

The indoor air VOC concentration and surface emissions were measured before and after the renovations. In the apartment renovated by using 'method 2', the residual surface emissions were measured also from the concrete surface after the 3-week heating and ventilation period.

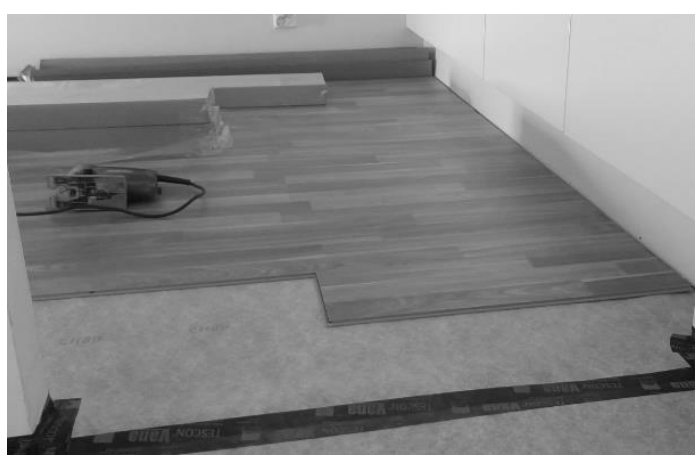

Fig. 1. cTrap installed on the floor with taped seams and edges. New laminate flooring is being installed on top of the cTrap.

\subsection{Studied spaces and samples}

The indoor air VOC concentrations were measured in 17 apartments before the renovation. Measurements were taken from different floors and facades (cardinal directions). Control samples were taken approximately 1 to 5 months after finishing the renovations. Indoor air control samples were taken from three 'repair method 1' apartments and one 'repair method 2' apartment. Three of the control samples were paired samples from apartments that had been studied before renovation. One control sample was from an apartment that had not been assessed before renovation. Surface emissions were measured before renovations in three apartments. Emission control samples were taken in two (different) apartments, both of which had been renovated with 'repair method 1'. The amount, timing and location of control measurements were partly determined by the case client and the project schedule.

\subsection{Indoor air and surface emission measurement methods}

Indoor air VOC concentrations of were measured by active sampling in Tenax TA adsorbent according to the standard ISO16000-6 (2006). Specific emission rate, (SER) of surface emissions of VOCs was measured by using the field and laboratory emission chamber (FLEC) according to NT Build 484 standard (Nordtest 1998) onsite from unbroken flooring surface. Samples were analysed in the laboratory of Finnish Institute of Occupational Health, FIOH. The laboratory-reported method uncertainty of the VOC-analysis is on average $19 \%$. In this paper results of 2-EH are reported as toluene equivalent, since national guideline values are given in this form. During the indoor air and surface VOC measurements the ambient conditions of temperature and relative humidity were measured by using HMP42/HMI41-device (Vaisala Oy, Finland). The apartments have an HVAC system (forced in- and exhaust ventilation) that was kept on in normal setting during the measurements. 


\section{Results}
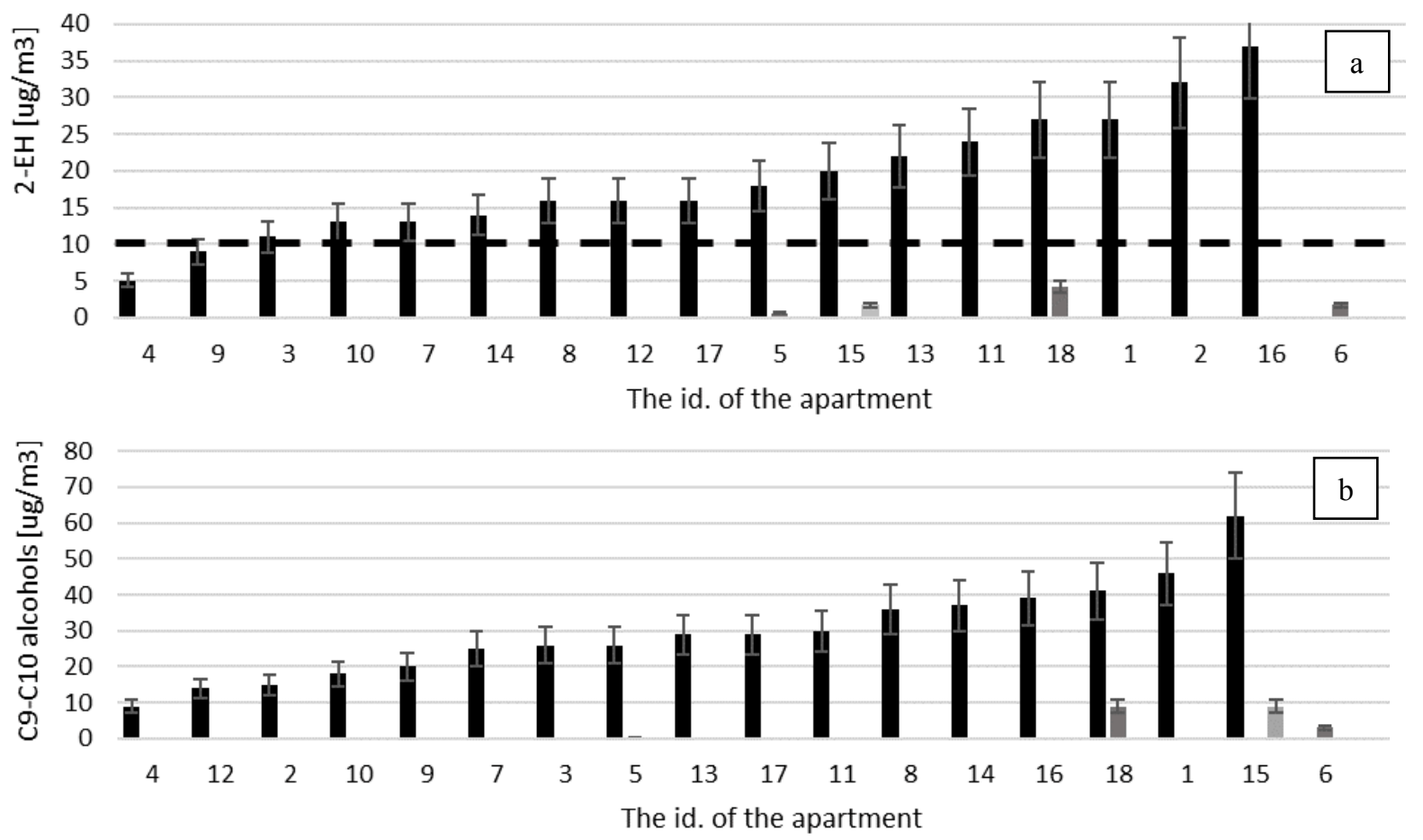

घ before renovation —after renovation, "method 1" घafter renovation, "method 2"

Fig. 2. Indoor air concentration of 2-ethyl-hexanol (a) and C9-C10 alcohols (b) in the case apartments before and after renovation. The black bars show the before renovation values and grey bars show the after renovation (control sample) values. The results are arranged in order of increasing VOC concentration before renovation. Most apartments were studied only before the renovation. The vertical dotted line in (a) shows the $10 \mu \mathrm{g} / \mathrm{m}^{3}$ action limit set by the Finnish Ministry of Social Affairs and Health for 2-EH. Error bars describe the $\pm 19 \%$ uncertainty of the analysis.

\subsection{Indoor air}

The indoor air concentrations of 2-EH before and after renovation are shown in figure $2 \mathrm{a}$ and the concentrations of $\mathrm{C} 9-\mathrm{C} 10$ alcohols in figure $2 \mathrm{~b}$.

Before the renovation, 2-EH concentration in indoor air varied between $5-37 \mu \mathrm{g} / \mathrm{m}^{3}$ (average $19 \mu \mathrm{g} / \mathrm{m}^{3}$ ). After renovation the concentration varied between 0,6 $4 \mu \mathrm{g} / \mathrm{m}^{3}$ (average $3 \mu \mathrm{g} / \mathrm{m}^{3}$ ). In paired samples taken from the same apartment before and after renovation, the amount of 2-EH decreased by $84-97 \%$.

The measured concentration of C9-C10 alcohols in indoor air varied between 9-62 $\mu \mathrm{g} / \mathrm{m}^{3}$ (average $30 \mu \mathrm{g} / \mathrm{m}^{3}$ ) before the renovation. After renovation the concentration varied between $0,4-9 \mu \mathrm{g} / \mathrm{m}^{3}$ (average $5 \mu \mathrm{g} / \mathrm{m}^{3}$ ). In paired samples taken from the same apartment before and after renovation, the amount of $\mathrm{C} 9-\mathrm{C} 10$ alcohols decreased by $88-98 \%$.

\subsection{Surface emissions}

Before the renovation the surface emission rate varied between $55-64 \mu \mathrm{g} / \mathrm{m}^{2} \mathrm{~h}$ for 2-EH and between 65 - $130 \mu \mathrm{g} / \mathrm{m}^{2} \mathrm{~h}$ for C9-C10 alcohols (Fig. 3). The surface emission rates from the milled concrete surface of the apartment renovated by using "method 2 " were 110 $\mu \mathrm{g} / \mathrm{m}^{2} \mathrm{~h}$ and $130 \mu \mathrm{g} / \mathrm{m}^{2} \mathrm{~h}$ for 2-EH and C9-C10 alcohols, correspondingly. The measurement was done after the 3week ventilation period but before cTrap installation.

After renovation including the installation of cTrap 2-EH and C9-C10 alcohols were no longer found (the emission rates were under the determination limit) (Fig $3)$.

\section{Discussion and conclusions}

In the case building, clearly elevated concentrations of 2$\mathrm{EH}$ and $\mathrm{C} 9-\mathrm{C} 10$ alcohols were detected in indoor air, and the same compounds were found emitting in high rates from the surface of the plastic flooring material of the studied apartments. The average concentration of 2-EH of indoor air was $19 \mu \mathrm{g} / \mathrm{m}^{3}$.

The Finnish Ministry of Social Affairs and Health has set the action limit of $2-\mathrm{EH}$ to $10 \mu \mathrm{g} / \mathrm{m}^{3}$ [8]. The value indicates the level at which necessary actions should be taken to eliminate or limit the harm it may cause. Considering the analysis uncertainty, the indoor air concentrations exceeded the action limit in 14 of the 17 studied apartments. The average concentration of C9$\mathrm{C} 10$ alcohols in indoor air was $30 \mu \mathrm{g} / \mathrm{m}^{3}$. No specific action limit is set to C9-C10 alcohols [8], however, according to Valvira (National Supervisory Authority for 

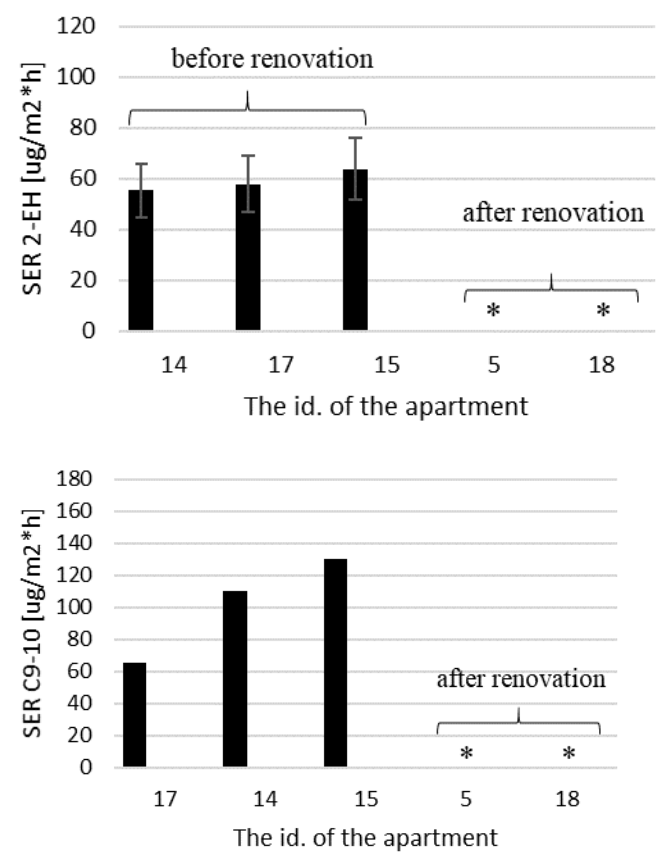

Fig. 3. Specific emission rates of 2-EH (a) and C9-C10 alcohols (b) from intact floor surface measured before and after renovation. The results marked with an asterisk $(*)$ were below the determination limit of $1 \mu \mathrm{g} / \mathrm{m}^{2} \mathrm{~h}$.

Welfare and Health), C9 - C10 alcohols are suspected to cause symptoms in ambient concentrations exceeding 10-50 $\mu \mathrm{g} / \mathrm{m}^{3}$ [9].

Repairing floors by removing the original flooring material and using cTrap decreased the ambient concentrations of 2-EH by 84-97 \% and of C9-C10 alcohols by $88-98 \%$. After renovation the concentration of 2-EH was below the $10 \mu \mathrm{g} / \mathrm{m}^{3}$ action limit in all studied apartments. Also, the measured level of C9-C10 alcohols was $<10 \mu \mathrm{g} / \mathrm{m}^{3}$. No clear or consistent differences were seen between 'repair method 1' and 'repair method 2' apartments, however, the total number of 'after-renovation' measurements was small (four apartments in total).

After renovation the originally elevated specific emission rates of the above-mentioned compounds were below the determination limit, so it can be concluded that repair successfully stopped the residual emissions of the VOCs from concrete and old screed to indoor air. The low levels of 2-EH and C9-C10 alcohols that still could be detected in indoor air after the renovation most probably derived from tertiary emissions of the compounds that had absorbed to other materials, such as ceiling and wall levelling and paint before renovation.

The time between renovation and control sampling varied between 1 to 5 months in the case apartments. The measured VOC concentrations or surface emission rates after renovation did not correlate with the time span.

By using 'repair method 1' the goals set for the indoor air quality were achieved. In this repair method plastic carpet, carpet glue and top layer of screed were removed and replaced with a thin layer of new screed, cTrap and laminate flooring. The concrete and remaining screed were not removed, baked or encapsulated. Repair method saved both time and expenses of the renovation, made dust protection easier and caused less noise and harm to the building users than 'repair method 2' or some heavier repair method.

One of the limitations of the study is the lack of negative control, ie. an apartment that would have been renovated otherwise similarly but without cTrap. Unfortunately, such an experiment was not possible in this study, since all case apartments were in use and the building owner required the renovation to be 'on the safe side'. In order to assess the exact role of cTrap in diminishing the emissions, comparative experiments should be made.

Because the follow-up time of our study was rather short, only one to five months after the renovation, the long-term performance of the chosen repair method cannot be directly deduced from the results. A particular concern would be the saturation of the adsorption cloth, which might lead into the diffusion of VOCs through the material into the indoor air. The risk can be roughly evaluated by comparing the measured 2-EH adsorption capacity of cTrap $\left(13.5 \mathrm{~g} / \mathrm{m}^{2} \pm 6 \%\right.$ [6]) with the expected total amount of VOC residue in the concrete. By using the data obtained in the study of Jokipii [5] the adsorption depth of 2-EH in the concrete should be no more than $60 \mathrm{~mm}$, and the average concentration of 2$\mathrm{EH}$ be ca. $3 \mathrm{mg} / \mathrm{kg}$. Thus, the concrete would hold up to $0,45 \mathrm{~g} / \mathrm{m}^{2}$ of $2-\mathrm{EH}$ in total. As cTrap's adsorption capacity is approximately 30 -times higher the product should be able to absorb the 2-EH and other residual emissions in their entity.

\section{References}

1. MJ. Mendell. Indoor Air 17: 259-277. (2007)

2. A. Tuomainen, M. Seuri, A. Sieppi. Int Arch Occup Environ Health 77, 3 (2004)

3. Å. Westberg, D. Momcilovic, F. Björk and S. Karlsson. Polym Degrad Stabil 95, 9 (2010)

4. F. Björk, C-A. Eriksson, S. Karlsson and F. Khabbaz. Constr Build Mater 17, 3 (2003)

5. M. Jokipii. Thesis. Häme University of Applied Sciences (In Finnish) (2014)

6. P. Markowicz ja L. Larsson. J Microbiol Methods 91, p. 290-294 (2012)

7. P. Markowicz ja L. Larsson. Atmos Environ 106, p. 376-381 (2012)

8. STMa 545/2015. Decree of the Ministry of Social Affairs and Health on Health-related Conditions of Housing and Other Residential Buildings and Qualification Requirements for Third-party Experts. (In Finnish) (2015)

9. Valvira. Asumisterveysasetuksen soveltamisohje, Osa III Asumisterveysasetus \& 14-19 (In Finnish) (2016) 